\title{
Antagonist targeting microRNA-146a protects against lithium-pilocarpine-induced status epilepticus in rats by nuclear factor- $\kappa B$ pathway
}

\author{
HUILONG ZHANG ${ }^{1 *}$, YUN QU ${ }^{2 *}$ and AIHUA WANG ${ }^{3}$ \\ Departments of ${ }^{1}$ Neurology and ${ }^{2}$ Emergency, The Affiliated Yantai Yuhuangding Hospital of Qingdao University, \\ Yantai, Shandong 264000; ${ }^{3}$ Department of Neurology, Qianfoshan Hospital Affiliated to Shandong University, \\ Jinan, Shandong 250014, P.R. China
}

Received February 15, 2017; Accepted December 5, 2017

DOI: $10.3892 / \mathrm{mmr} .2018 .8465$

\begin{abstract}
Previous studies have indicated that nuclear factor $-\kappa \mathrm{B}(\mathrm{NF}-\kappa \mathrm{B})$ has an important role in the pathogenesis of epilepsy. The aim of the present study was to evaluate the expression of microRNA (miRNA)-146a, phosphorylated (p)-P65/P65, B-cell lymphoma-2(Bcl-2)/Bcl-2-associated X protein (Bax) and pro-inflammatory cytokines, such as interleukin (IL)-6, IL-1 $\beta$ and tumor necrosis factor (TNF- $\alpha$ ) in the brain tissue of rats with epilepsy. Sprague-Dawley rats were used to establish the epilepsy model using the lithium-pilocarpine method. The expression of miR-146a, pro-inflammatory cytokines, P-glycoprotein (P-gp), Bcl-2/Bax and p-P65/P65 were assessed by reverse transcription-semi-quantitative polymerase chain reaction, enzyme-linked immunosorbent assay and western blotting, respectively. Hematoxylin and eosin staining was used to determine the pathology of epilepsy. The current findings revealed that the expression of miR-146a was greater in the model group compared with the control group, and that the expression of miR-146a reached a maximum at 7 days post-treatment. The expression levels of IL-1 $\beta$, IL- 6 and TNF- $\alpha$ were significantly reduced in the miR-146a antagonist group when compared with the model group. Additionally, the expression levels of P-gp and p-P65/P65 were significantly reduced following the addition of the miR-146a antagonist, whereas the expression levels of Bcl-2/Bax significantly increased under the same conditions. Therefore, the NF- $\kappa \mathrm{B}$ pathway and miR-146a may be potential therapeutic targets in the treatment of epilepsy.
\end{abstract}

Correspondence to: Dr Aihua Wang, Department of Neurology, Qianfoshan Hospital Affiliated to Shandong University, 16766 Jingshi Road, Jinan, Shandong 250014, P.R. China

E-mail: 0806wangaihua@sina.com

${ }^{*}$ Contributed equally

Key words: miR-146a, epilepsy, nuclear factor-кB pathway, pro-inflammatory cytokines

\section{Introduction}

Epilepsy is a serious, long-term and debilitating brain disorder, identifiable by paroxysmal bursts of activity within cortical neurons, which affects approximately $1 \%$ of the world population $(1,2)$. Although epilepsy frequently develops in childhood, its symptoms may last a lifetime (3). Epilepsy is characterized by a predisposition to recurring episodes of seizures and abnormally synchronized neuronal discharges with the potential to disrupt the function of the brain region from which they originate, or through which they pass (1). Despite currently available antiepileptic drugs and surgeries for focal epilepsy being available, both clinical treatments have some side effects, including headache, dizziness, fatigue and at axia. Additionally, $>20 \%$ of all patients with epilepsy continue to have the symptoms following treatment $(4,5)$. Therefore, the identification of new biological markers for treatment against epilepsy is of great importance. In recent years, there has been a number of studies investigating molecular causes of epilepsy (6-9). A previous study suggested the involvement of microRNAs (miRNAs) in the lesion of epilepsy (6). miRNAs are single-stranded molecules, between 18-24 nucleotides in length, that block the expression of protein-coding genes at the post transcriptional level by directing translational repression or mRNA destabilization, or a combination of the two (7). Many post transcriptional inflammation-associated miRNAs, such as the brain-enriched miRNA (miR)-146a, have been previously identified to be involved in the regulation of inflammatory responses in epileptic rats and adult patients $(8,9)$.

The nuclear factor- $\kappa \mathrm{B}(\mathrm{NF}-\kappa \mathrm{B})$ pathway is an important intracellular signaling pathway involved in the early stress response (10-12). A previous study suggested that $N F-\kappa B$ acts as a key point of convergence for multiple stress signals, including intracellular $\mathrm{Ca}^{2+}$ changes, pro-inflammatory cytokines and oxidative stress (10). The pathway is also involved in the modulation of neuronal excitability and seizure susceptibility (13). Additionally, downstream events activated by $\mathrm{NF}-\kappa \mathrm{B}$, such as inflammation and oxidative stress, are also known to be activated by seizure activity $(14,15)$. 
The present study induced an epilepsy animal model using the lithium-pilocarpine method. The expression of miR-146a was detected using reverse transcription-semi-quantitative polymerase chain reaction (RT-sqPCR). The expression levels of pro-inflammatory cytokines, including interleukin (IL) $-1 \beta$, IL-6 and tumor necrosis factor- $\alpha$ (TNF- $\alpha$ ), were determined using an ELISA. Additionally, the protein expression levels of P-glycoprotein (P-gp), B-cell lymphoma-2 (Bcl-2)/Bcl2-associated $\mathrm{X}$ (Bax) and phosphorylated (p)-P65/P65 were quantified using western blot analysis. The findings of the present study may aid the evaluation of miR-146a regulation as a potential new anti-epilepsy therapy, and suggests that miR-146a antagonist treatment of epilepsy may be associated with $\mathrm{NF}-\kappa \mathrm{B}$ pathway.

\section{Materials and methods}

Animals. A total of 72 adult male Sprague-Dawley rats (Weitonglihua Biomart, Beijing, China), weighing 180-220 g, 6-8 weeks were housed in a temperature $\left(24 \pm 0.5^{\circ} \mathrm{C}\right)$ and $12-\mathrm{h}$ light-dark cycle with a 50-60\% humidity and had free access to food and water. Prior to the experiments, the animals were allowed to habituate to the housing facilities for 1 week. The present study was conducted with approval from the Animal Ethics Committee of the affiliated Yantai Yuhuangding Hospital of Qingdao University (Yantai, China).

Epilepsy induction. In order to induce status epilepticus (SE), rats were intraperitoneally (i.p.) injected $127 \mathrm{mg} / \mathrm{kg}$ with lithium chloride (CAS: 7447-41-8; Santa Cruz Biotechnology, Inc., Dallas, TX, USA), followed $20 \mathrm{~h}$ later by anatropine (Tianjin Kaitong Chemical Reagent Co., Ltd., Tianjin, China) i.p. $(0.1 \mathrm{mg} / \mathrm{kg})$ injection and $30 \mathrm{~min}$ later by pilocarpine hydrochloride (cat. no. P6503-5G, Sigma-Aldrich; Merck KGaA, Darmstadt, Germany) treatment (40 mg/kg; i.p.). SE was characterized by continuous limbic seizures $30 \mathrm{~min}$ after the last treatment. The severity of seizures was evaluated using the Racine scale (16): 0, No response; 1 , motor arrest and twitching vibrissae; 2 , chewing and head bobbing; 3, forelimb clonus; 4 , forelimb clonus and rearing; and 5, rearing and falling. Rats exhibiting continuous seizures at stage $\mathrm{V}$ of the Racine scale were used for the subsequent experiments, were then divided into two sections. Section I, consisted of two groups: i) 8 Naive rats were used as control; and ii) $40 \mathrm{SE}$ rats were used to evaluate the expression of miR-146a. Section II, consisted of three groups: i) 8 naive rats were used as control; ii) SE model group $n=8$; and iii) $1 \mathrm{nmol} \mathrm{miR-146a} \mathrm{inhibitor-treated} \mathrm{(Guangzhou} \mathrm{RiboBio} \mathrm{Co.,}$ Ltd., Guangzhou, China) group (IN group). The rats belonging to the IN group were treated with $1 \mathrm{nmol}$ miR-146a inhibitor $2 \mathrm{~h}$ post-pilocarpine injection.

$R T$-sqPCR. Animals were sacrificed following deep anesthesia with an i.p. injection of $10 \%$ chloral hydrate $(500 \mathrm{mg} / \mathrm{kg})$ at day $1,3,7,14$ and 30 following-SE induction. Following decapitation, the brain was removed as previously described (17) for RNA isolation. Total RNA was extracted with TRIzol reagent (Gibco; Thermo Fisher Scientific, Inc., Waltham, MA, USA) and both the concentration and the purity of RNA were then determined at 260/280 nm using a NanoDrop spectrophotometer. Isolated RNA (1 $\mu \mathrm{g})$ was then subjected to cDNA synthesis. cDNA synthesis was conducted in a $14 \mu \mathrm{l}$ reaction buffer, containing $1 \mu \mathrm{l}$ reverse transcriptase $(50 \mathrm{U})$ and $1 \mu 1$ ologo $(\mathrm{dT})$ primer, according to manufacturer's protocol (Takara Biotechnology Co., Ltd., Dalian, China). The following temperature protocol was used for the reverse transcription: $37^{\circ} \mathrm{C}$ for $15 \mathrm{~min}, 85^{\circ} \mathrm{C}$ for $5 \mathrm{sec}$ and $4^{\circ} \mathrm{C}$ until subsequent use for qPCR. The sequences of the primers for qPCR wereas follows: miRNA-146a, forward $(\mathrm{F})$, 5'-CAGTGCGTGTCGTGGAGT-3' and reverse (R), 5'-GGG TGAGAACTGAATTCCA-3'; U6 F, 5'-GCTTCGGCAGCA CATATACTAAAAT-3' and R, 5'-CGCTTCACGAATTTG CGTGTCAT-3'. Reaction conditions were as follow: $95^{\circ} \mathrm{C}$ for $30 \mathrm{sec}$, followed by 35 cycles of $95^{\circ} \mathrm{C}$ for $10 \mathrm{sec}, 60^{\circ} \mathrm{C}$ for $15 \mathrm{sec}$ and $72^{\circ} \mathrm{C}$ for $15 \mathrm{sec}$. Each $20 \mu \mathrm{l}$ reaction system consisted of $2 \mu \mathrm{l}$ cDNA, $10 \mu \mathrm{l}$ SYBR Premix Ex Taq II (Sangong Biotech Co., Ltd., Shanghai, China) and $10 \mu \mathrm{mol} / 1$ of both forward and reverse primers (Sangong Biotech Co., Ltd.). U6 was used to normalize the mRNA. The results were analyzed on an $1 \%$ agarose gel (Sangong Biotech Co, Ltd.) with ethidium bromide and the relative intensity of the bands was determined using Image $\mathbf{J}$ software (National Institutes of Health, Bethesda, MD, USA).

Histopathological analysis. The hippocampus was dehydrated in increasing concentrations of ethanol, rinsed with Histoclear (National Diagnostics, Atlanta, GA, USA), embedded in paraffin and then cut on a microtome into $5-\mu \mathrm{m}$ thick slices. Following dewaxing, slides were boiled for $48 \mathrm{~h}$ at $45^{\circ} \mathrm{C}$ and then for $1 \mathrm{~h}$ at $60^{\circ} \mathrm{C}$. The sections were stained with hematoxylin and eosin for 10 and 5 min respectively at room temperature. All stained sections were then assessed under a light microscope (magnification, $\mathrm{x} 400$ ).

Western blot analysis. The brain tissue samples were homogenized in lysis buffer (20 mMTris, $1 \%$ Triton-X-100, $0.05 \%$ $\mathrm{SDS}, 5 \mathrm{mg}$ of sodium deoxycholate, $150 \mathrm{mMNaCl}$ and $1 \mathrm{mM}$ PMSF) containing a mixture of protease and phosphatase inhibitors. The protein concentrations were then determined using a Bicinchoninic acid Protein Assay reagent kit (Beyotime Institute of Biotechnology, Shanghai, China). Equal quantity of protein (40 $\mu \mathrm{g} /$ lane) were separated by $10 \%$ SDS-PAGE and then transferred to polyvinylidenedifluoride membranes. The nonspecific binding of antibodies was blocked with 5\% non-fat dried milk in PBS, then incubated with the following primary antibodies: Rabbit monoclonal Bcl-2 (1:500; cat. no. 3498, Cell Signaling Technology, Inc., Danvers, MA, USA), rabbit monoclonal Bax (1:500; cat. no. 5023; Cell Signaling Technology, Inc.), rabbit monoclonal P-gp (1:500; cat. no. ab170964; Abcam, Cambridge, UK), rabbit monoclonal p-P65 (1:500; cat. no. 3033; Cell Signaling Technology, Inc.), rabbit monoclonal P65 (1:500; cat. no. 59674; Cell Signaling Technology, Inc.) at $4^{\circ} \mathrm{C}$ overnight. Following incubation with the horseradish peroxidase-conjugated goat anti-rabbit immunoglobulin G secondary antibody (1:5,000; cat. no. SC-2004; Santa Cruz Biotechnology, Inc., Dallas, TX, USA) at $4^{\circ} \mathrm{C}$ for $1 \mathrm{~h}$ and developed with electrochemiluminescence (ECL) Western Blotting Substrate (BD Biosciences, Franklin Lakes, NJ, USA). Data was analyzed using Quantity One 1D image analysis software (version 4.4; Bio-Rad Laboratories, Inc., Hercules, CA, USA). 


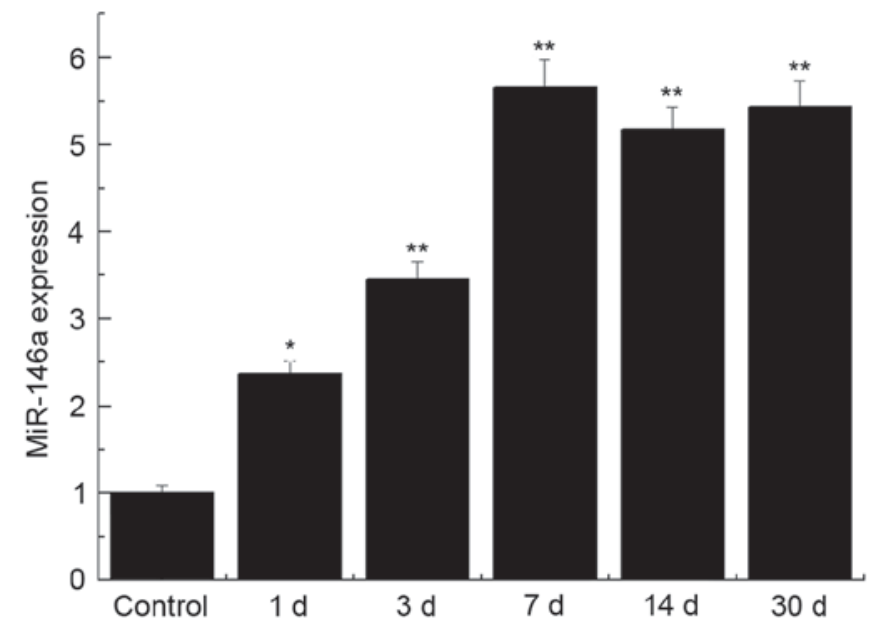

Figure 1. Induction of epilepsy upregulated the transcription of miR-146a. ${ }^{*} \mathrm{P}<0.05,{ }^{* *} \mathrm{P}<0.01$ vs. control group. miR, microRNA.

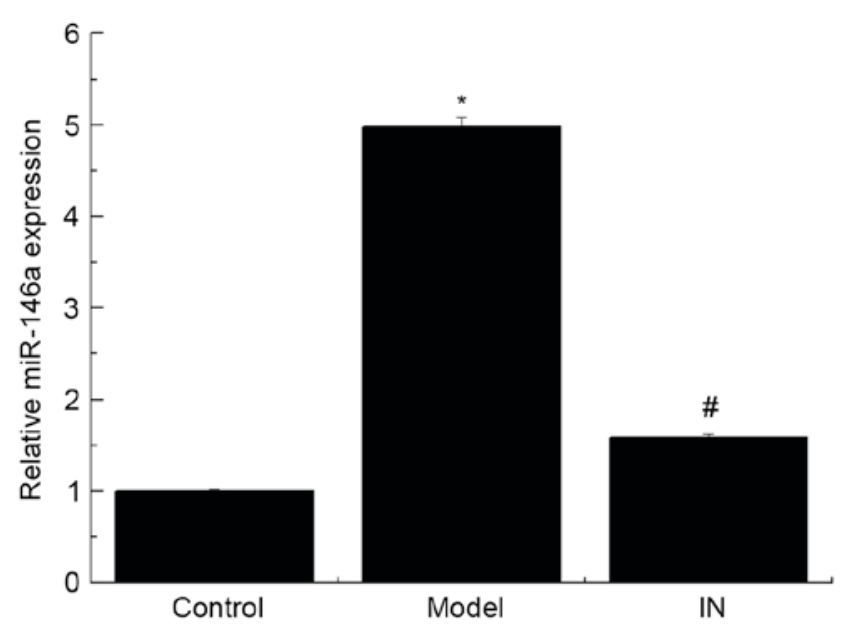

Figure 2. Administation of miR-146a antagonist reduced the expression of miR-146a. ${ }^{*} \mathrm{P}<0.05$ vs. control group. ${ }^{\#} \mathrm{P}<0.05$ vs. model group. miR, microRNA; IN, inhibitor group.

Enzyme-linked immunosorbent assay (ELISA). ELISA kits for rat IL-1 $\beta$ (cat. no. PI303; Beyotime Institute of Biotechnology), TNF- $\alpha$ (cat. no. PT516; Beyotime Institute of Biotechnology) and IL-6 (cat. no. PI328; Beyotime Institute of Biotechnology) were used to determine cytokine levels in cerebrospinal fluid (CSF) following the manufacturer's protocols. The plates were quantified at $450 \mathrm{~nm}$ using amicroplate reader.

Statistical analysis. Data are expressed as mean \pm standard deviation. Statistical differences were evaluated using SPSS version 19.0 (IBM Corporation, Armonk, NY, USA). Statistical analysis was performed using one-way analysis of variance. $\mathrm{P}<0.05$ was considered to indicate a statistically significant difference.

\section{Results}

$R T$-sqPCR. miR-146a expression levels were significantly upregulated in the brain tissue of the SE group when compared with control group at day $1,3,7,14$ and $30(\mathrm{P}<0.05 ; \mathrm{P}<0.01$;
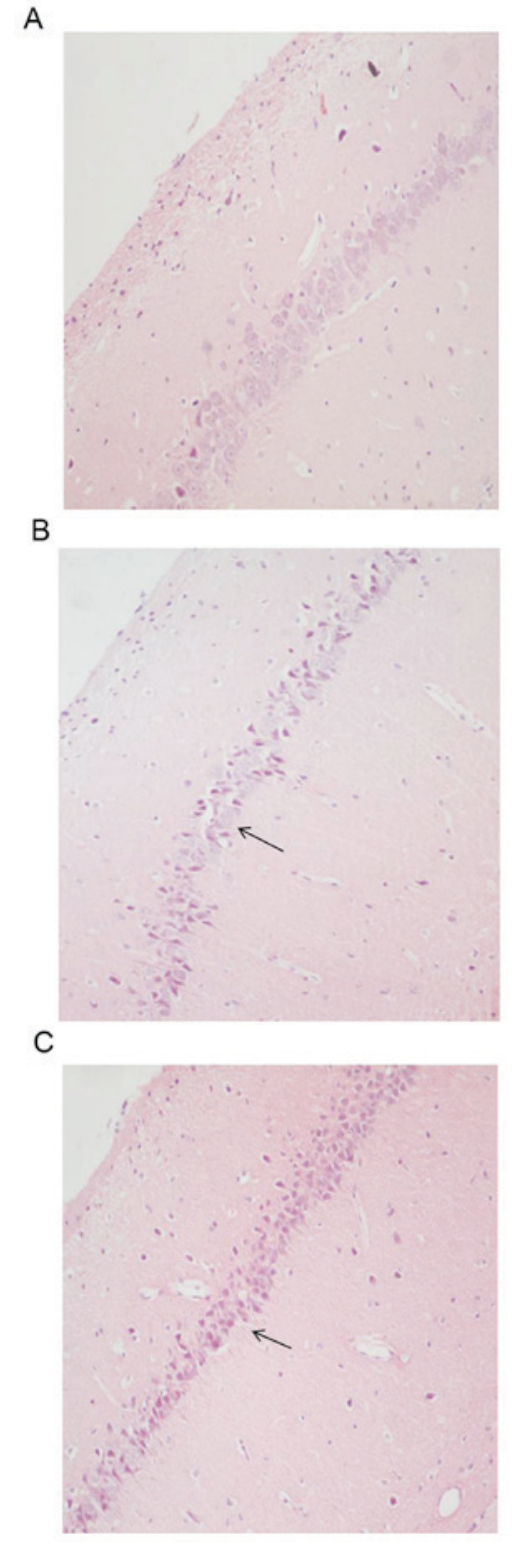

Figure 3. Hematoxylin and eosin staining analysis of morphological changes in the hippicampus of the different treatment groups. (A) Control group. (B) Model group. (C) Inhibitor group. The arrows indicate neuronal cells that are missing from the model group but are present in the inhibitor group. Magnification, $\mathrm{x} 400$.

Fig. 1). The upregulation of miR-146a expression reached a maximum at the day 7 following pilocarpine treatment $(\mathrm{P}<0.01)$. The rats were treated with the miR-146a inhibitor, the expression of miR-146a was significantly reduced (Fig. 2; $\mathrm{P}<0.01)$. However, no significant difference between the control group and the IN group was identified ( $\mathrm{P}>0.05)$.

Histopathological analysis. Examination of hippocampal CA3 and CA4 regions in the control group revealed compactly arranged and healthy pyramidal cells with clear nuclei, and intact cell membranes (Fig. 3A). Compared to the control group, hematoxylin and eosin staining of the model group 7 days post-pilocarpine treatment displayed numerous shrunken neurons, neuronal cell loss, disordered tissue structure in hippocampal CA3 and CA4 are as and abnormal cell morphology (Fig. 3B). Rats treated with the miR-146a inhibitor 
A

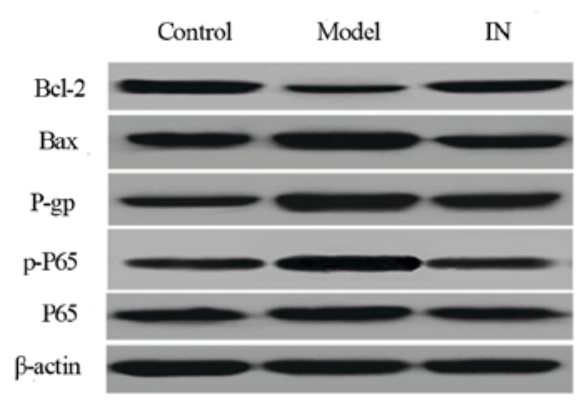

$\mathrm{C}$

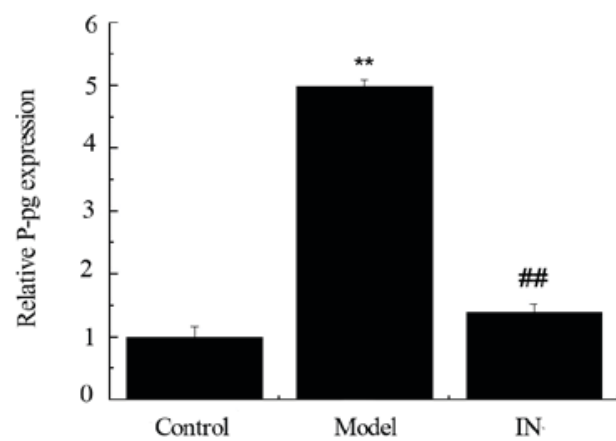

B

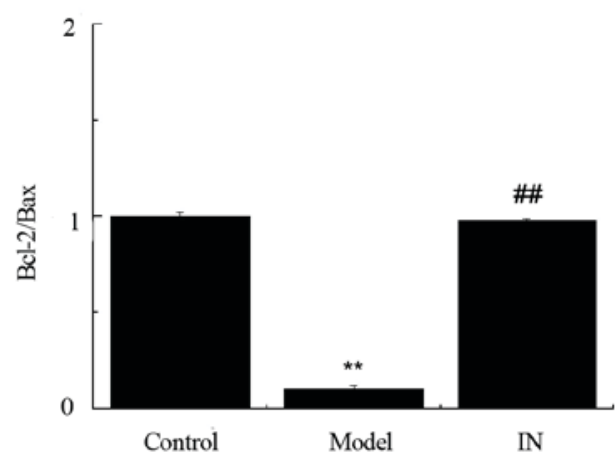

D

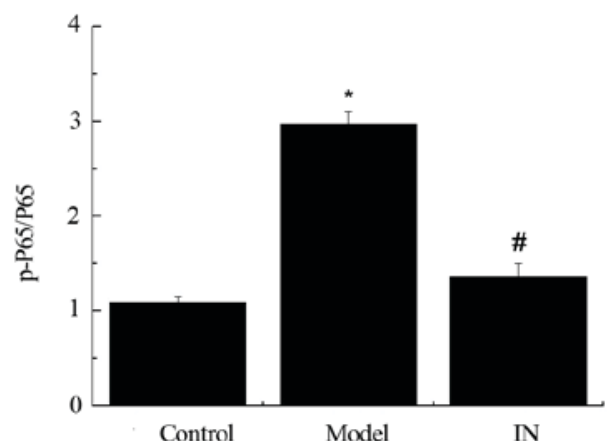

Figure 4. (A) Western blot analysis of expression of (B) Bcl-2/Bax, (C) P-gp, (D) p-P65/P65 in rats. ${ }^{*} \mathrm{P}<0.05$, " $\mathrm{P}<0.01$ vs. control group. ${ }^{*} \mathrm{P}<0.05$, ${ }^{\# t} \mathrm{P}<0.01$ vs. model group. IN, inhibitor group; Bcl-2, B-cell lymphoma; Bax, Bcl2-associated X; p, phosphorylated; P-gp, P-glycoprotein.

A



B

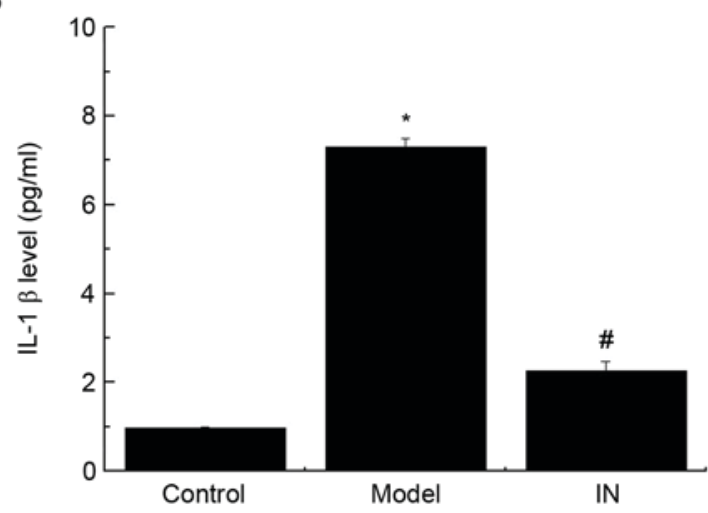

C

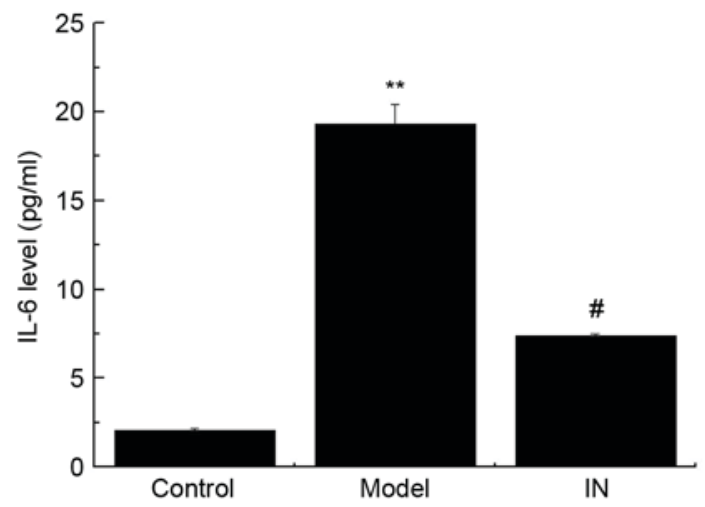

Figure 5. miR-146a inhibitor reduced (A) TNF- $\alpha$, (B) IL-1 $\beta$ and (C) IL-6 expression levels in CSF following pilocarpine treatment. ${ }^{*} \mathrm{P}<0.05,{ }^{* *} \mathrm{P}<0.01 \mathrm{vs.}$ control group. ${ }^{\#} \mathrm{P}<0.05,{ }^{\# \#} \mathrm{P}<0.01$ vs. model group. IN, inhibitor; TNF- $\alpha$, tumor necrosis factor- $\alpha$; IL, interleukin; CSF, cerebrospinal fluid. 
exhibited significantly reduced levels of neuronal cell loss and other morphological signs of damage (Fig. 3C).

Western blot analysis. P-gp and p-P65/P65 expression was significantly increased in the hippocampus of the model group compared with the control group (Fig. 4; $\mathrm{P}<0.01$ ). Compared with model group, the miR-146a inhibitor-treated group (IN group) significantly downregulated P-gp and p-P65/P65 expression. Conversely, the expression level ratio of Bcl-2/Baxin hippocampal tissues in the model group was significantly lower when compared withthe control group $(\mathrm{P}<0.01$; Fig. 4B). The treatment of miR-146a antagonist significantly reversed this as $\mathrm{Bcl}-2 / \mathrm{Bax}$ ratio was increased in the IN group when compared with model group $(\mathrm{P}<0.01)$. These findings suggest that the miR-146a inhibitor reduces the expression of $\mathrm{P}-\mathrm{gp}$ and $\mathrm{p}-\mathrm{P} 65 / \mathrm{P} 65$ and increases the expression of $\mathrm{Bcl}-2 / \mathrm{Bax}$ in rats.

Enzyme-linked immunosorbent assay (ELISA). Previous studies have demonstrated that pro-inflammatory cytokines are involved in SE (18-20). Therefore, the current study aimed to investigate the alterations in pro-inflammatory cytokine expression levels in CSF. As presented in Fig. 5, significant increases in TNF- $\alpha$, IL-1 $\beta$, and IL-6 expression levels in CSF of model rats when compared with the control group were observed. However, the addition of the miR-146a inhibitor reversed the effect of pilocarpine treatment by preventing the increase in the expression levels of TNF- $\alpha$, IL- $1 \beta$ and IL-6 (Fig. $5 ; \mathrm{P}<0.05$ ). These findings suggest that the miR-146a antagonist attenuates the expression of TNF- $\alpha$, IL-1 $1 \beta$ and IL- 6 in the CSF of SE rats.

\section{Discussion}

miR-146a is a typical multifunctional miR and hasa key role in several biological processes. miR-146a was upregulated during epileptogenesis in an animal model and patients $(4,21)$. Aronica et al reported an altered expression pattern of miR-146a in epileptic rats and in the temporal lobe of epilepsy patients, and demonstrated high expression levels of miR-146a in the latent and chronic stages of disease inthe rat model and human tissues (22). The present study investigated the dynamic expression of miR-146a in a lithium-pilocarpine-induced epilepsy rat model and the possible use of miR-146a as a target against epilepsy. The present findings revealed a marked upregulation of miR-146a in the model group, whereas rats treated with the miR-146a antagonist had reduced miR-146 expression levels. This finding was consistent with that reported by the Hu et al study (23).

The transcription factor, NF- $\mathrm{kB}$ is an important regulator of immune and inflammatory processes, and has previously been described to be involved in neuropathological processes, including seizures and epilepsy $(24,25)$. Furthermore, a previous study demonstrated that NF- $\kappa \mathrm{B}$ is activated in response to convulsion stimulation in rodent models (26). When NF- $\kappa \mathrm{B}$ is activated, it binds to the promoter domain of the target genes through DNA NF- $\mathrm{kB}$ sequences. A number of cytokines and chemokines are involved in this pathway following NF- $\mathrm{KB}$ activation (27). Previous study has identified the P-glycoprotein (P-gp) as a regulator of the NF- $\kappa B$ signaling pathway at the blood-brain barrier (BBB) in a number of pathogenic scenarios (28). It has previously been suggested that antiepileptic drugs may use P-gp as an efflux pump, which is located at the endothelial cell membrane in the brain (29). The expression of P-gp in the brain is increased under prolonged seizure conditions, such as SE or frequent spontaneous seizures (30). In the present study, the expression levels of NF- $\mathrm{KB}$ and P-gp were markedly increased in lithium-pilocarpine-induced epilepsy; however, the addition of the miR-146a inhibitor was able to block this effect. The findings obtained by the current study are in line with those found in previous studies. Experimental models and clinical studies have confirmed that a prolonged seizure or SE may lead to neuronal death in the brain (31). The underlying mechanism by which neurons die following brain injury, such as a stroke or SE, has revealed the involvement of apoptosis in neuronal cell death (32). Apoptosis is regulated by several signaling pathways, in which the Bcl-2 protein family has an important role (33). Proteins of particular interest within the $\mathrm{Bcl}-2$ family are $\mathrm{Bcl}-2$, an anti-apoptoticprote in which may prevent cell death and Bax, a homolog of Bcl-2 which may promote apoptosis (34). The Bcl-2/Bax ratio has previously been used to determine the anti-apoptosis capability (35). Treatment with the miR-146a inhibitor may protect neurons from lithium-pilocarpine-induced toxicity and reverse lithium-pilocarpine-induced neuronal injury, partially through inhibition of the aforementioned apoptotic pathways.

$\mathrm{NF}-\mathrm{KB}$ is an important inflammatory regulator, which is responsible for the activation of downstream pro-inflammatory cytokines, including IL- $1 \beta$, IL- 6 and TNF- $\alpha$, in SE models or patients (36). Previous studies have revealed that inflammation contributes to epileptogenesis (18-20). Ravizza et al (18) identified that expression of IL-1 $\beta$ was markedly induced in the acute stage $4 \mathrm{~h}$ following SE. Furthermore, it has been revealed that seizures may allow circulating proteins to enter the brain through the BBB (6). IL-6 is a cytokine that is upregulated following different types of tissue trauma and inflammation. IL- 6 and TNF- $\alpha$ levels were observed as being upregulated in the SE model and in patients following a seizure $(37,38)$. The present study demonstrated an upregulation of TNF- $\alpha$, IL- $1 \beta$ and IL-6 in the model group when compared with the control group. Additionally, it was determined that treatment with miR-146a may significantly reduce the expression levels of pro-inflammatory cytokines compared to those observed in the model group. The findings of the present study therefore suggest that activation of the cytokine network is associated with epilepsy.

The present study may not explicitly explain the enacting mechanism of the miR-146a inhibitor; however, the current findings may provide a novel the rapeutictarget for antiepileptic therapy. Further investigation is required to establish whether the change in expression of pro-inflammatory cytokines and the altered activity of the NF- $\mathrm{kB}$ pathway occur via distinct or related mechanisms in the SE model.

In conclusion, the use of miR-146a inhibitor for the blocking of the pathogenic activation of the NF- $\mathrm{KB}$ pathway contributing to epileptogenesis in the SE brain may have a protective function. The current study demonstrated that there was an upregulation 
of miR-146a expression in lithium-pilocarpine-induced epilepsy. The current findings also demonstrated an upregulation of miR-146a expression associated with seizures. The expression patterns of pro-inflammatory cytokines, including TNF- $\alpha$, IL-1 $\beta$ and IL- 6 and their regulator, NF- $\kappa B$, suggest an interactive relationship. The findings of the current study support the proposal that pro-inflammatory cytokines and the $\mathrm{NF}-\kappa \mathrm{B}$ pathway have a role in the pathogenesis of SE development. Additionally, the findings of the present study suggest that modulation of miR-146a expression by using an inhibitor may act asa potential target for antiepileptic therapy.

\section{References}

1. Engel T and Henshall DC: Apoptosis, Bcl-2 family proteins and caspases: The $\mathrm{ABC}$ of seizure-damage and epileptogenesis? Int J Physiol Pathophysiol Pharmacol 1: 97-115, 2009.

2. Cai Z, Li S, Li S, Song F, Zhang Z, Qi G, Li T, Qiu J, Wan J, Sui H and Guo $\mathrm{H}$ : Antagonist targeting microRNA-155 protects against lithium-pilocarpine-induced status epilepticus in C57BL/6 mice by activating brain-derived neurotrophic factor. Front Pharmacol 7: 129, 2016.

3. Huang $\mathrm{H}$, Zhou $\mathrm{H}$ and Wang $\mathrm{N}$ : Recent advances in epilepsy management. Cell Biochem Biophys 73: 7-10, 2015.

4. Omran A, Peng J, Zhang C, Xiang QL, Xue J, Gan N, Kong H and Yin F: Interleukin-1 $\beta$ and microRNA-146a in an immature rat model and children with mesial temporal lobe epilepsy. Epilepsia 53: 1215-1224, 2012.

5. Stephen LJ, Kelly K, Mohanraj R and Brodie MJ: Pharmacological outcomes in older people with newly diagnosed epilepsy. Epilepsy Behav 8: 434-437, 2006.

6. Li MM, Li XM, Zheng XP, Yu JT and Tan L: MicroRNAs dysregulation in epilepsy. Brain Res 1584: 94-104, 2014.

7. Bartel DP: MicroRNAs: Target recognition and regulatory functions. Cell 136: 215-233, 2009.

8. Aronica E, Fluiter K, Iyer A, Zurolo E, Vreijling J, van Vliet EA, Baayen JC and Gorter JA: Expression pattern of miR-146a, an inflammation-associated microRNA, in experimental and human temporal lobe epilepsy. Eur J Neurosci 31: 1100-1107, 2010.

9. Li X, Gibson G, Kim JS, Kroin J, Xu S, van Wijnen AJ and Im HJ: MicroRNA-146a is linked to pain-related pathophysiology of osteoarthritis. Gene 480: 34-41, 2011.

10. Miller JA, Kirkley KA, Padmanabhan R, Liang LP, Raol YH, Patel M, Bialecki RA and Tjalkens RB: Repeated exposure to low doses of kainic acid activates nuclear factor kappa $B$ $(\mathrm{NF}-\kappa \mathrm{B})$ prior to seizure in transgenic $\mathrm{NF}-\kappa \mathrm{B} / \mathrm{EGFP}$ reporter mice. Neurotoxicology 44: 39-47, 2014.

11. Liang Y and Wang X: Developing a new perspective to study the health of survivors of Sichuan earthquakes in China: A study on the effect of post-earthquake rescue policies on survivors health-related quality of life. Health Res Policy Syst 11: 41, 2013

12. Liang Y and Lu P: Effect of occupational mobility and health status on life satisfaction of Chinese residents of different occupations: Logistic diagonal mobility models analysis of cross-sectional data on eight Chinese provinces. Int J Equity Health 13: 15, 2014

13. Lubin FD, Ren Y, Xu X and Anderson AE: Nuclear factor-kappa B regulates seizure threshold and gene transcription following convulsant stimulation. J Neurochem 103: 1381-1395, 2007.

14. Vezzani A, Friedman A and Dingledine RJ: The role of inflammation in epileptogenesis. Neuropharmacology 69: 16-24, 2013.

15. Rowley S and Patel M: Mitochondrial involvement and oxidative stress in temporal lobe epilepsy. Free Radical Biol Med 62 121-131, 2013.

16. Meffert MK and Baltimore D: Physiological functions for brain NF-kappaB. Trends Neurosci 28: 37-43, 2005.

17. da Costa AV, Calábria LK, Nascimento R, Carvalho WJ, Goulart LR, Espindola FS: The streptozotocin-induced rat model of diabetes mellitus evidences significant reduction of myosin-Va expression in the brain. Metab Brain Dis 26: 247-251, 2011.

18. Ravizza T, Rizzi M, Perego C, Richichi C, Velísková J, Moshé SL, De Simoni MG and Vezzani A: Inflammatory response and glia activation in developing rat hippocampus after status epilepticus. Epilepsia 46 (Suppl 5): 113-117, 2005.
19. Patterson KP, Brennan GP, Curran M, Kinney-Lang E, Dubé C, Rashid F, Ly C, Obenaus A and Baram TZ: Rapid, coordinate inflammatory responses after experimental febrile status epilepticus: Implications for epileptogenesis. eNeuro 2: 0034-15, 2015.

20. Itoh K, Ishihara Y, Komori R, Nochi H, Taniguchi R, Chiba Y, Ueno M, Takata-Tsuji F, Dohgu S and Kataoka Y: Levetiracetam treatment influences blood-brain barrier failure associated with angiogenesis and inflammatory responses in the acute phase of epileptogenesis in post-status epilepticus mice. Brain Res 1652: $1-13,2016$.

21. Faraoni I, Antonetti FR, Cardone J and Bonmassar E: miR-155 gene: A typical multifunctional microRNA. Biochim Biophys Acta 1792: 497-505, 2009.

22. Aronica E, van Vliet EA, Hendriksen E, Troost D, Lopes da Silva FH and Gorter JA: Cystatin C, a cysteine protease inhibitor, is persistently up-regulated in neurons and glia in a rat model for mesial temporal lobe epilepsy. Eur J Neurosci 14: 1485-1491, 2001

23. Hu K, Zhang C, Long L, Long X, Feng L, Li Y and Xiao B: Expression profile of microRNAs in rat hippocampus following lithium-pilocarpine-induced status epilepticus. Neurosci Lett 488: 252-257, 2011.

24. Mattson MP and Camandola S: NF-kappaB in neuronal plasticity and neurodegenerative disorders. J Clin Invest 107: 247-254, 2001.

25. Mattson MP and Meffert MK: Roles for NF-kappaB in nerve cell survival, plasticity, and disease. Cell Death Differ 13: 852-860, 2006.

26. Yu Z, Zhou D, Cheng G and Mattson MP: Neuroprotective role for the p50 subunit of NF-kappaB in an experimental model of Huntington's disease. J Mol Neurosci 15: 31-44, 2000.

27. Yu N, Di Q, Liu H, Hu Y, Jiang Y, Yan YK, Zhang YF and Zhang YD: Nuclear factor-kappa B activity regulates brain expression of P-glycoprotein in the kainic acid-induced seizure rats. Mediat Inflamm 2011: 670613, 2011.

28. Zhang J, Zhang M, Sun B, Li Y, Xu P, Liu C, Liu L and Liu X: Hyperammonemia enhances the function and expression of P-glycoprotein and Mrp2 at the blood-brain barrier through NF-кB. J Neurochem 131: 791-802, 2014.

29. Lazarowski A, Czornyj L, Lubienieki F, Girardi E, Vazquez S and D'Giano C: ABC transporters during epilepsy and mechanisms underlying multidrug resistance in refractory epilepsy. Epilepsia 48 (Suppl 5): S140-S149, 2007.

30. Volk H, Potschka H and Löscher W: Immunohistochemical localization of P-glycoprotein in rat brain and detection of its increased expression by seizures are sensitive to fixation and staining variables. J Histochem Cytochem 53: 517-531, 2005.

31. Thom M, Zhou JM, Martinian L and Sisodiya S: Quantitative post-mortem study of the hippocampus in chronic epilepsy: Seizures do not inecvitably cause neuronal loss. Brain 128: 1344-1357, 2005.

32. Kondratyev A and Gale $\mathrm{K}$ : Intracerebral injection of caspase-3 inhibitor prevents neuronal apoptosis after kainic acid-evoked status epilepticus. Brain Res Mol Brain Res 75: 2216-224, 2000.

33. Heath-Engel HM, Chang NC and Shore GC: The endoplasmic reticulum in apoptosis and autophagy: Role of the BCL-2 protein family. Oncogene 27: 6419-6433, 2008.

34. Sanchez A, Tripathy D, Yin X, Luo J, Martinez J and Grammas P: Pigment epithelium-derived factor (PEDF) protects cortical neurons in vitro from oxidant injury by activation of extracellular signal-regulated kinase (ERK) $1 / 2$ and induction of Bcl-2. Neurosci Res 72: 1-8, 2012.

35. Zeren T, Inan S, Vatansever HS and Sayhan S: Significance of apoptosis related proteins on malignant transformation of ovarian tumors: A comparison between Bcl-1/Bax ratio and p53 immunoreactivity. Acta Histochem 116: 1251-1258, 2014.

36. Vezzani A and Granata T: Brain inflammation in epilepsy: Experimental and clinical evidence. Epilepsia 46: 1724-1743, 2005.

37. Vezzani A and Baram TZ: New roles for interleukin-1 Beta in the mechanisms of epilepsy. Epilepsy Curr 7: 45-50, 2007.

38. Peltola J, Palmio J, Korhonen L, Suhonen J, Miettinen A, Hurme M, Lindholm D and Keränen T: Interleukin-6 and interleukin-1 receptor antagonist in cerebrospinal fluid from patients with recent tonic-clonic seizures. Epilepsy Res 41: 205-211, 2000. 